\title{
Effect of Polyphenols on Production of Steroid Hormones from Human Adrenocortical NCI-H295R Cells
}

\author{
Eri Hasegawa, ${ }^{a}$ Saori Nakagawa, ${ }^{a}$ Momoe Sato,${ }^{a}$ Eiichi Tachikawa, ${ }^{b}$ and Susumu Yamato ${ }^{*, a}$ \\ ${ }^{a}$ Department of Bio-Analytical Chemistry, Niigata University of Pharmacy and Applied Life Sciences; 265-1 \\ Higashijima, Akiha-ku, Niigata 956-8603, Japan: and ${ }^{b}$ Department of Endocrine and Neural Pharmacology, Tokyo \\ University of Pharmacy and Life Sciences; 1432-1 Horinouchi, Hachioji, Tokyo 192-0392, Japan. \\ Received July 18, 2012; accepted November 20, 2012
}

\begin{abstract}
Modulating steroid hormone levels is a curative and preventive measure for Cushing's syndrome, aldosteronism, and various stress-triggered symptoms. Polyphenols have been reported to inhibit steroidogenic enzymes such as $3 \beta$-hydroxysteroid dehydrogenase (3 $\beta$-HSD) and aromatase. However, evidence for their inhibitory effects is fragmentary because it has been determined in studies with small groups of steroid hormones. To investigate the effects of steroids on complete steroidogenic pathways, comprehensive analysis of steroid hormones is necessary. Here we cultured forskolin-stimulated NCI-H295R, a human adrenocortical carcinoma cell line, in the presence of a polyphenol and employed GC-MS to simultaneously determine the levels of nine steroid hormones (pregnenolone, progesterone, deoxycorticosterone, aldosterone, 17 $\alpha$-hydroxyprogesterone, dehydroepiandrosterone, androstenedione, testosterone, and estradiol) in cell culture supernatant. We found that daidzein, genistein, apigenin, hesperetin, naringenin, and eriodictyol significantly reduced deoxycorticosterone and androstenedione levels $(p<0.05)$, suggesting inhibition of $3 \beta$-HSD by these polyphenols. Apigenin was more potent than other polyphenols in increasing the levels of pregnenolone and $17 \alpha$-hydroxyprogesterone, suggesting that it inhibits cytochrome P450 (CYP) 17 and CYP21, as well as $3 \beta$-HSD. Real-time reverse transcription polymerase chain reaction showed that apigenin significantly downregulated the expression levels of $3 \beta-H S D, C Y P 17$, and $C Y P 21 \mathrm{mRNA}(p<0.05)$. This is the first study to demonstrate the inhibitory effects of apigenin on CYP17 and CYP21.
\end{abstract} nol

Key words apigenin; cytochrome P450 (CYP)17; CYP21; pregnenolone; 17 $\alpha$-hydroxyprogesterone; polyphe-

Steroid hormones are secreted by the adrenal cortex and play pivotal roles in stress response, immune response, antiinflammatory actions, carbohydrate metabolism, protein catabolism, and electrolyte homeostasis. ${ }^{1)}$ Disrupting the secretion of these hormones has a serious impact on human health. For example, in Cushing's syndrome, hyperproduction of cortisol results in redistribution of fat to the face (moon face), hypertension, central obesity, and striae distensae. In cases of aldosteronism, hyperproduction of aldosterone induces renal reabsorption of sodium and water, which leads to a rise in circulating blood volume and hypertension. In addition, under stressful conditions, such as those related to deteriorating socioeconomic situations, chronic work-related stress, anxiety, and depression, the neuroendocrine response is upregulated, and the resulting cortisol hyperproduction triggers insulin resistance. Furthermore, the hypothalamic-pituitary-adrenal axis is hyperactivated under chronic stress, which in turn induces abdominal obesity, thereby leading to metabolic syndrome. ${ }^{2)}$

Agents and supplements that modulate steroid hormone levels play pivotal roles in treating the above diseases and conditions. Several food constituents have already been reported as steroid hormone inhibitors. For example, water-soluble low-molecular weight $\beta$-1,3-D-glucan was reported to inhibit stress-induced increases in blood corticosterone levels, ${ }^{3)}$ and $\mathrm{n}-3$ fatty acids in fish oil have been shown to suppress stress-induced increases in plasma cortisol levels. ${ }^{4)}$ It was also reported that saponin of Panax ginseng blocks morphineinduced increases in serum corticosterone levels. ${ }^{5)}$ Such food constituents can be consumed easily as part of a daily diet,

The authors declare no conflict of interest. are safer than pharmaceutical agents, and have a milder effect.

Polyphenols are common food constituents abundant in tea, legumes, fruits, and vegetables, ${ }^{6}$ and they have been shown to have cardio-protective, anti-cancer, and neuro-protective effects, as well as the ability to reduce blood glucose levels. ${ }^{7}$ Polyphenols can be classed as flavonoids and non-flavonoids; the latter group includes phenolic acids, stilbenes, and lignans. Flavonoids are further divided into flavanols, such as in green tea and chocolate, isoflavones, in legumes such as soy beans, flavanones in citrus fruits, and flavones in celery and parsley. Of them, isoflavones with hydroxyl-groups at $\mathrm{C} 7$ and $\mathrm{C}^{\prime}$, such as daidzein and genistein, are known as phytoestrogens. They show structural similarity to estrogen and exert weak estrogenic actions after binding to the estrogen receptor. ${ }^{6,8)}$ Intake of these phytoestrogens appears to reduce estradiol levels via inhibition of aromatase, thereby suppressing breast cancer cells. $^{8)}$ Furthermore, genistein is associated with anti-prostate cancer effects, and intake of isoflavones has been reported to reduce prostate volume. ${ }^{8)}$ These favorable actions of polyphenols appear to be exerted via the inhibition of steroidogenic enzymes. For example, daidzein, genistein, apigenin, and naringenin inhibit $3 \beta$-hydroxysteroid dehydrogenase $\left(3 \beta\right.$-HSD) ${ }^{9-11)}$ while daidzein and genistein inhibit cytochrome P450 (CYP) 21. ${ }^{12)}$ In addition, isoflavones inhibit both $3 \beta$-HSD and $17 \beta$-hydroxysteroid dehydrogenase $\left(17 \beta\right.$-HSD). ${ }^{13)}$

However, the various actions of polyphenols on steroid hormones have to date being determined through studies with small groups of steroid hormones. This means that findings have been partial and do not demonstrate all possible actions of polyphenols in steroidogenic pathways from cholesterol to steroid hormones. Many enzymes are involved in the 
steroidogenic pathways, but reports relating to the inhibitory effects of polyphenols on steroidogenesis are limited to the enzymes $3 \beta$-HSD and $17 \beta$-HSD. On the other hand, few reports address the inhibitory effects of polyphenols on enzymes in the progesterone pathway and the dehydroepiandrosterone (DHEA) pathway. Simultaneous determination of nine steroid hormones-pregnenolone, progesterone, deoxycorticosterone, aldosterone, $17 \alpha$-hydroxyprogesterone, DHEA, androstenedione, testosterone, and estradiol-will provide comprehensive knowledge on the effect of polyphenols on all steroidogenic pathways.

Several methods have been reported in which steroid hormones were determined by GC-MS. ${ }^{14,15)}$ However, these methods are somewhat complicated because they require two or three reactions, such as $n$-butylboronic cyclization, methyloxime derivatization, and trimethylsilyl (TMS) derivatization.

In this study, we aimed to improve the simultaneous determination of nine steroid hormones to make TMS derivatization more simple and accurate, and determined the levels of nine steroid hormones secreted from human adrenocortical NCI-H295R cells stimulated with forskolin in the presence of 11 types of polyphenols. Real-time reverse transcription polymerase chain reaction (RT-PCR) to detect the expression levels of steroidogenic enzyme mRNA was also performed to clarify the inhibition step in the steroidogenic pathways.

\section{MATERIALS AND METHODS}

Materials A human adrenocortical carcinoma cell line NCI-H295R was purchased from American Type Culture Collection (Mannasas, VA, U.S.A.). Hesperetin (purity, 99\%), apigenin (purity, $\geq 97 \%$ ), and forskolin were purchased from Funakoshi (Tokyo, Japan), and (-)-epicatechin (EC; purity, $\geq 98 \%$ ), (-)-epigallocatechin gallate (EGCG; purity, $\geq 98 \%$ ), (-)-epicatechin gallate (ECG; purity, $\geq 98 \%$ ), catechin (purity, $99 \%$ ), daidzein (purity, $\geq 98 \%$ ), and genistein (purity, 99.9\%) were from Cosmo Bio (Tokyo, Japan). Naringenin (purity, $\geq 95 \%$ ) and eriodictyol (purity, $\geq 95 \%$ ) were from Sigma-Aldrich (St. Louis, MO, U.S.A.), and epigallocatechin (EGC; purity, $\geq 98 \%$ ) was from Wako Pure Chemical Industries, Ltd. (Osaka, Japan). For cell culture, Dulbecco's modified Eagle's medium (DMEM), nutrient mixture F-12 Ham $(1: 1)$ medium, and penicillin-streptomycin were purchased from Sigma-Aldrich, ITS $+{ }^{\text {TM }}$ Premix and Nu-Serum ${ }^{\mathrm{TM}}$ supplements were from BD Biosciences (Bedford, MA, U.S.A.), phosphate buffered saline (PBS) was from Nissui Pharmaceutical (Tokyo Japan), and dimethyl sulfoxide (DMSO) was from Nakalai Tesque (Kyoto, Japan).

DHEA (purity, $>99 \%$ ), estradiol (purity, $>98 \%$ ), androstenedione (purity, $>98 \%$ ), pregnenolone (purity, $>98 \%$ ), progesterone (purity, 99\%), deoxycorticosterone (purity, $>98 \%$ ), $17 \alpha$-hydroxyprogesterone (purity, $\geq 95 \%$ ), and aldosterone (purity, $>95 \%$ ) were purchased form Sigma-Aldrich, and testosterone (purity, $>97 \%$ ) and $5 \alpha$-cholestane as an internal standard were from Wako Pure Chemical Industries, Ltd. Ethyl acetate (HPLC grade) and $n$-hexane (residual agricultural chemicals and PCB testing grade) were purchased from Wako Pure Chemical Industries, Ltd. Tri-Sil HTP Reagent was from Thermo Fisher Scientific (Waltham, MA, U.S.A.).

For molecular biology, total RNA extraction reagent (RNAiso Plus), PrimeScript RT reagent kit, and SYBR premix
Ex Taq were purchased from Takara Bio (Shiga, Japan). Ethanol (molecular biology grade), isopropyl alcohol (molecular biology grade), and chloroform (JIS high-quality guaranteed grade) were from Wako Pure Chemicals. Diethylpyrocarbonate (DEPC)-treated water (genetic engineering grade) was from Nippon Gene (Tokyo, Japan).

GC-MS Analysis GC-MS was performed using the GCMS-QP2010 plus mass spectrometer (electron ionization (EI) method) with the AOC-20s auto-sampler, AOC-20i autoinjector (all from Shimadzu, Kyoto, Japan), and a DB-5MS column (length, $30 \mathrm{~m}$; inner diameter, $0.25 \mathrm{~mm}$; film thickness, $0.25 \mu \mathrm{m}$; Agilent Technologies, Santa Clara, CA, U.S.A.). GC conditions were as follows: carrier gas, helium; flow rate, $0.96 \mathrm{~mL} / \mathrm{min}$; injection temperature, $230.0^{\circ} \mathrm{C}$; injection mode, splitless; initial column temperature, $180^{\circ} \mathrm{C}$; column temperature program, hold at $180^{\circ} \mathrm{C}$ for $1 \mathrm{~min}$, heat at $20^{\circ} \mathrm{C} / \mathrm{min}$ to $292^{\circ} \mathrm{C}$, hold at $292^{\circ} \mathrm{C}$ for $3 \mathrm{~min}$, heat at $1^{\circ} \mathrm{C} / \mathrm{min}$ to $295^{\circ} \mathrm{C}$, heat at $10^{\circ} \mathrm{C} / \mathrm{min}$ to $300^{\circ} \mathrm{C}$, and hold at $300^{\circ} \mathrm{C}$ for $15 \mathrm{~min}$. Selected ion monitoring was performed to measure DHEA at $\mathrm{m} / \mathrm{z}$ $\underline{304}, 270,360$, estradiol at $\mathrm{m} / \mathrm{z} \underline{285}, 326,416$, androstenedione at $\mathrm{m} / \mathrm{z} 286,244$, testosterone at $\mathrm{m} / \mathrm{z} 226,270,360$, pregnenolone at $\overline{m / z} 298,332,388$, progesterone at $\mathrm{m} / \mathrm{z} \underline{272}, 229,314$, $17 \alpha$-hydroxyprogesterone at $\mathrm{m} / \mathrm{z} \underline{269}, 402,359$, deoxycorticosterone at $\mathrm{m} / \mathrm{z} 299,387$, aldosterone at $\mathrm{m} / \mathrm{z}$ 311, 401, 414, and $5 \alpha$-cholestane at $\mathrm{m} / \mathrm{z} 372,217,357$. The underlined $\mathrm{m} / \mathrm{z}$ value was used for the quantification ion.

Effects of Polyphenols on Levels of Steroid Hormones Produced by Forskolin-Stimulated Cells NCI-H295R cells $\left(2 \times 10^{6}\right.$ cells) were seeded in a $25 \mathrm{~cm}^{2}$ flask and cultured for $72 \mathrm{~h}$ in DMEM:F-12 containing 1\% ITS+TM Premix, $2.5 \%$ $\mathrm{Nu}-\mathrm{Serum}^{\mathrm{TM}}$, and $1 \%$ penicillin-streptomycin (culture medium). Cells were washed with phosphate buffered saline twice and treated with forskolin (final concentration, $3 \mu \mathrm{M}$ ) in the presence or absence of $30 \mu \mathrm{M}$ of a polyphenol (EGCG, ECG, EGC, EC, catechin, daidzein, genistein, apigenin, hesperetin, naringenin, or eriodictyol; Fig. 1) in the serum-free medium for $24 \mathrm{~h}$ to obtain cell culture supernatant samples. ${ }^{16)}$ For daidzein, genistein, apigenin, hesperetin, naringenin, and eriodictyol, which changed steroid hormone levels, a series of concentrations $(0,1,3,10,30 \mu \mathrm{M})$ were tested to determine whether their effects were dose-dependent. Stock solutions of forskolin and each polyphenol were prepared in DMSO, and the concentrations of DMSO in cell culture were $<0.125 \%$.

GC-MS of Steroid Hormones in Cell Culture Supernatant Samples A cell culture supernatant $(500 \mu \mathrm{L})$ was placed in a centrifuge tube containing the internal standard $(0.25 \mu \mathrm{g}){ }^{14)}$ After adding $1.5 \mathrm{~mL}$ of ethyl acetate, the tube was shaken for $5 \mathrm{~min}$ and centrifuged at $3000 \mathrm{rpm}$ for $5 \mathrm{~min}$. The resulting top layer (ethyl acetate) was subjected to solvent extraction twice. After removing the solvent under nitrogen gas flow, $50 \mu \mathrm{L}$ of Tri-Sil HTP Reagent was added to perform TMS derivatization for $30 \mathrm{~min}$ at $60^{\circ} \mathrm{C}$ under a nitrogen atmosphere. After removing the solvent under nitrogen gas flow, the remaining residue was dissolved in $50 \mu \mathrm{L}$ of $n$-hexane, and $3 \mu \mathrm{L}$ of the solution was injected onto the GC-MS column for simultaneous determination of nine types of steroid hormones.

Expression of Steroidogenic Enzyme mRNA by RealTime RT-PCR Analysis NCI-H295R cells were cultured for $72 \mathrm{~h}$ in the culture medium and washed as described above. Cells were then cultured in the serum-free medium containing forskolin (final concentration, $30 \mu \mathrm{M}$ ) with or without apigenin 
<smiles>O=C(O[C@H]1Cc2c(O)cc(O)cc2O[C@H]1c1cc(O)c(O)c(O)c1)c1cc(O)c(O)c(O)c1</smiles>

1<smiles>Oc1cc(O)c2c(c1)O[C@H](c1ccc(O)c(O)c1)[C@H](O)C2</smiles><smiles>O=c1c(-c2ccc(O)cc2)coc2cc(O)cc(O)c12</smiles>

7<smiles>O=C1CC(c2ccc(O)cc2)Oc2cc(O)cc(O)c21</smiles>

10<smiles>Oc1cc(O)c2c(c1)O[C@@H](c1ccc(O)c(O)c1)CC2</smiles>

2<smiles>Oc1cc(O)c2c(c1)O[C@H](c1ccc(O)c(O)c1)[C@H](O)C2</smiles>

5<smiles>O=c1cc(-c2ccc(O)cc2)oc2cc(O)cc(O)c12</smiles>

8<smiles>O=C1CC(c2ccc(O)c(O)c2)Oc2cc(O)cc(O)c21</smiles>

11<smiles>[2H][C@@H]1Cc2c(O)cc(O)cc2O[C@@H]1c1cc(O)c(O)c(O)c1</smiles>

3<smiles>O=c1c(-c2ccc(O)cc2)coc2cc(O)ccc12</smiles>

6<smiles>COc1ccc(C2CC(=O)c3c(O)cc(O)cc3O2)cc1O</smiles>

9

Fig. 1. Skeletal Formulae of Polyphenols

(-)-Epigallocatechin gallate (1), (-)-epicatechin gallate (2), (-)-epigallocatechin (3), (-)-epicatechin (4), (+)-catechin (5), daidzein (6), genistein (7), apigenin (8), hesperetin (9), naringenin (10), and eriodictyol (11)

Table 1. Primers and PCR Conditions

\begin{tabular}{|c|c|c|c|c|c|c|}
\hline \multirow{2}{*}{ Gene } & & \multirow{2}{*}{ Nucleotide sequence $\left(5^{\prime} \rightarrow 3^{\prime}\right)$} & \multicolumn{4}{|c|}{ PCR condition } \\
\hline & & & Denaturation & Annealing & Elongation & Cycles \\
\hline \multirow[t]{2}{*}{$3 \beta-H S D$} & $\mathrm{~F}$ & GCGGCTAATGGGTGGAATCTA & $94^{\circ} \mathrm{C}, 20 \mathrm{~s}$ & $54^{\circ} \mathrm{C}, 20 \mathrm{~s}$ & $72^{\circ} \mathrm{C}, 40 \mathrm{~s}$ & 50 \\
\hline & $\mathrm{R}$ & CATTCTTGTTCAGGGCCTCAT & & & & \\
\hline \multirow[t]{2}{*}{ CYP17 } & $\mathrm{F}$ & AGCCGCACACCAACTATCAG & $95^{\circ} \mathrm{C}, 15 \mathrm{~s}$ & $64^{\circ} \mathrm{C}, 60 \mathrm{~s}$ & $72^{\circ} \mathrm{C}, 30 \mathrm{~s}$ & 50 \\
\hline & $\mathrm{R}$ & TCACCGATGCTGGAGTCAAC & & & & \\
\hline \multirow[t]{2}{*}{ CYP21 } & $\mathrm{F}$ & ACCTCAGTTTCTCCTTTATTGC & $95^{\circ} \mathrm{C}, 20 \mathrm{~s}$ & $95^{\circ} \mathrm{C}, 30 \mathrm{~s}$ & $60^{\circ} \mathrm{C}, 30 \mathrm{~s}$ & 40 \\
\hline & $\mathrm{R}$ & AGAGCCAGGGTCCTTCAC & & & & \\
\hline \multirow[t]{2}{*}{$h G A P D H$} & $\mathrm{~F}$ & ATGCCAGTGAGCTTCCCGTCAGC & $95^{\circ} \mathrm{C}, 30 \mathrm{~s}$ & $60^{\circ} \mathrm{C}, 30 \mathrm{~s}$ & $72^{\circ} \mathrm{C}, 30 \mathrm{~s}$ & 45 \\
\hline & $\mathrm{R}$ & GGTATCGTGGAAGAACTCATGAC & & & & \\
\hline
\end{tabular}

Key: F, forward; R, reverse.

(final concentration, $1000 \mu \mathrm{M}$ ) for $24 \mathrm{~h}$. After washing with PBS, cells were dissolved in $1 \mathrm{~mL}$ of RNAiso plus and stored at $-20^{\circ} \mathrm{C}$ until use. RNA extraction and reverse transcription were performed according to manufacturer instructions. Briefly, cell samples (in RNAiso plus) were mixed well with chloroform and centrifuged. RNA was recovered from the top layer by isopropanol precipitation. The RNA pellet was washed with ethanol and dissolved in DEPC-treated water. Reverse transcription was performed on a 96-well plate at $37^{\circ} \mathrm{C}$ for $15 \mathrm{~min}$ : each well contained $5 \mu \mathrm{L}$ of an appropriately 
A

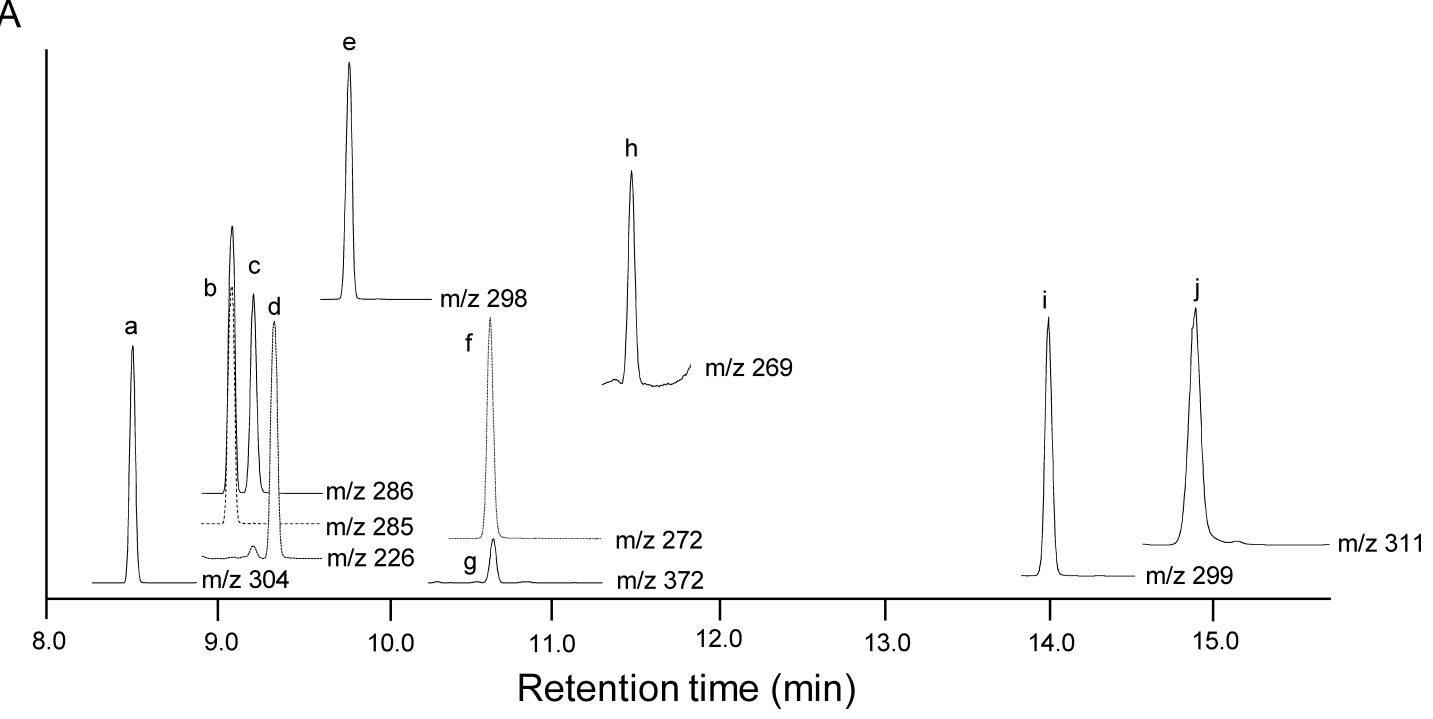

B

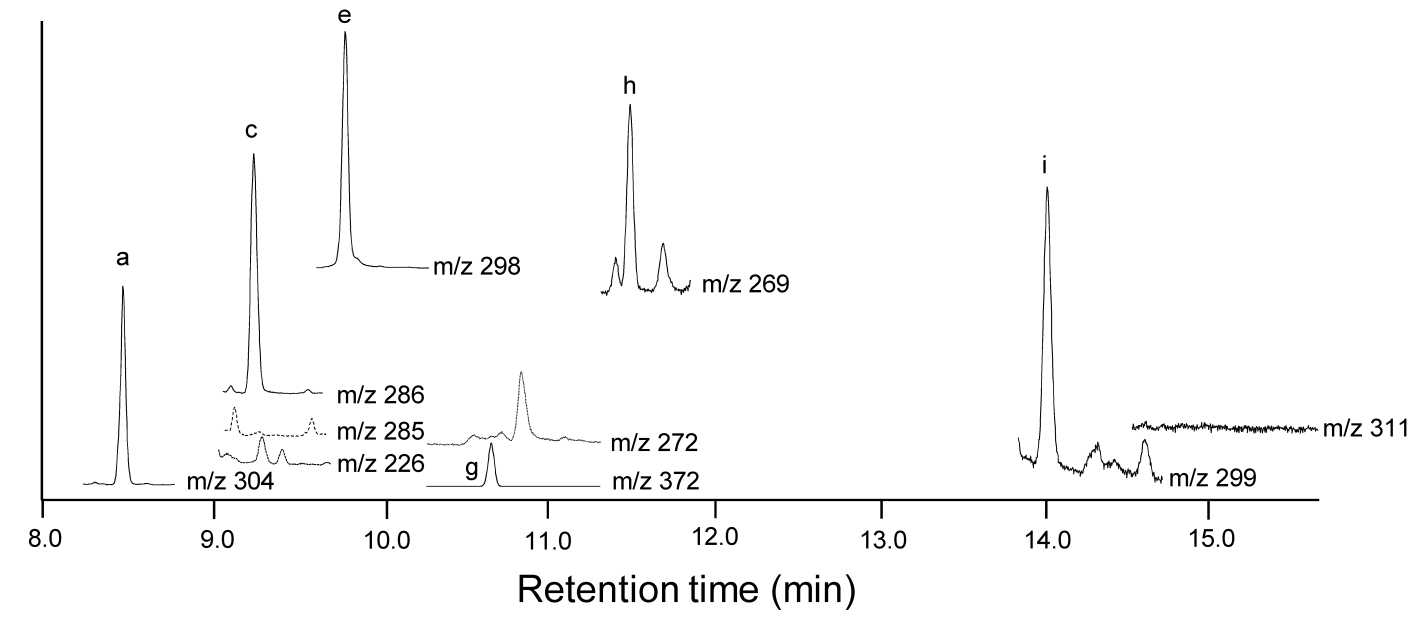

Fig. 2. Chromatogram of Standards and Cell Culture Supernatant

(A) Standards, (B) forskolin-stimulated cell culture supernatant. (a) Dehydroepiandrosterone (retention time, 8.5 min), (b) estradiol (9.1 min), (c) androstenedione $(9.2 \mathrm{~min})$, (d) testosterone $(9.3 \mathrm{~min})$, (e) pregnenolone $(9.8 \mathrm{~min})$, (f) $5 \alpha$-cholestane (internal standard, $10.7 \mathrm{~min})$, (g) progesterone (10.7 min), (h) $17 \alpha$-hydroxyprogesterone (11.5 min), (i) deoxycorticosterone (14.0 min) (j) aldosterone (14.9 min).

Table 2. Calibration and Assay Validation of Nine Steroids Using GC-MS

\begin{tabular}{|c|c|c|c|c|c|c|}
\hline Steroid & Linearity & Range (ng/mL) & $\begin{array}{c}\text { Correlation } \\
\text { coefficient }\left(R^{2}\right)\end{array}$ & Recovery (\%) & LOQ (ng/mL) & LOD $(\mathrm{ng} / \mathrm{mL})$ \\
\hline $\begin{array}{l}\text { Dehydroepiandrosterone } \\
\text { (DHEA) }\end{array}$ & $y=8.079 x+0.033$ & $1.2-250$ & 0.997 & $105.0 \pm 4.5$ & 1.2 & 0.4 \\
\hline Estradiol & $y=33.90 x+0.063$ & $0.2-250$ & 0.997 & $97.2 \pm 4.3$ & 0.2 & 0.05 \\
\hline Androstenedione & $y=4.835 x-0.004$ & $2.5-250$ & 0.999 & $107.5 \pm 6.7$ & 2.5 & 0.8 \\
\hline Testosterone & $y=8.362 x+0.067$ & $2.5-250$ & 0.993 & $98.5 \pm 5.5$ & 2.5 & 0.7 \\
\hline Pregnenolone & $y=8.283 x+0.050$ & $1.9-250$ & 0.995 & $98.3 \pm 4.1$ & 1.9 & 0.6 \\
\hline Progesterone & $y=3.668 x-0.004$ & $18.4-250$ & 0.999 & $100.7 \pm 8.6$ & 18.4 & 5.5 \\
\hline $17 \alpha$-Hydroxyprogesterone & $y=1.852 x-0.007$ & $10.2-250$ & 0.999 & $105.2 \pm 13.3$ & 10.2 & 3.1 \\
\hline Deoxycorticosterone & $y=10.52 x-0.080$ & $3.6-250$ & 0.997 & $98.8 \pm 8.9$ & 3.6 & 0.2 \\
\hline Aldosterone & $y=8.722 x-0.069$ & $3.0-250$ & 0.998 & $104.1 \pm 11.2$ & 3.0 & 0.9 \\
\hline
\end{tabular}

The LOD and the LOQ were determined as the concentration of nine steroid hormones giving a signal-to-noise ratio of 3 for LOD and 10 for LOQ. Recovery rate is expressed as mean \pm S.D. $(n=5)$.

diluted PrimeScript RT Master Mix solution and $5 \mu \mathrm{L}$ of RNA solution. The resulting cDNA solutions were further subjected to real-time PCR using SYBR Premix Ex Taq and a primer pair detecting $3 \beta$-HSD, CYP17, and CYP21 ${ }^{17-20)}$ (Table 1) on a 96-well plate. Each well contained $1 \mu \mathrm{L}$ of the cDNA solution and $24 \mu \mathrm{L}$ of the PCR mix. Threshold cycle $\left(C_{t}\right)$ values were determined by the second derivative maximum method. ${ }^{21)}$ The housekeeping gene $h G A P D H$ was used for normalization of 


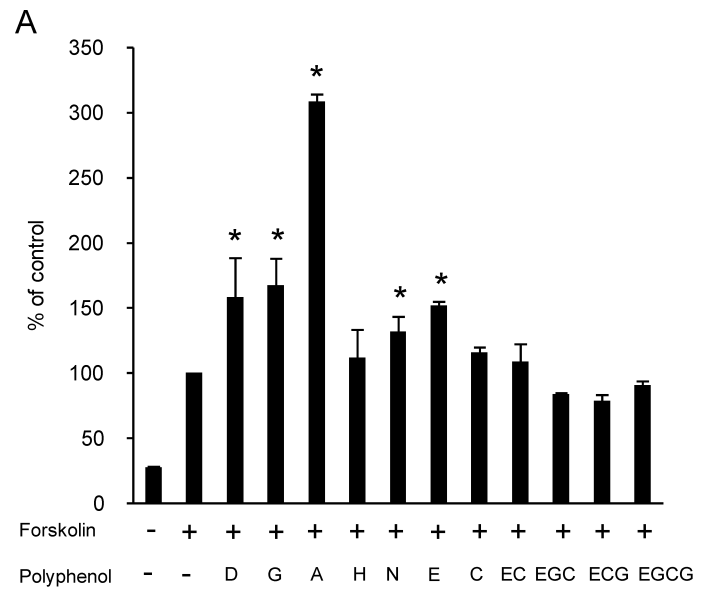

B
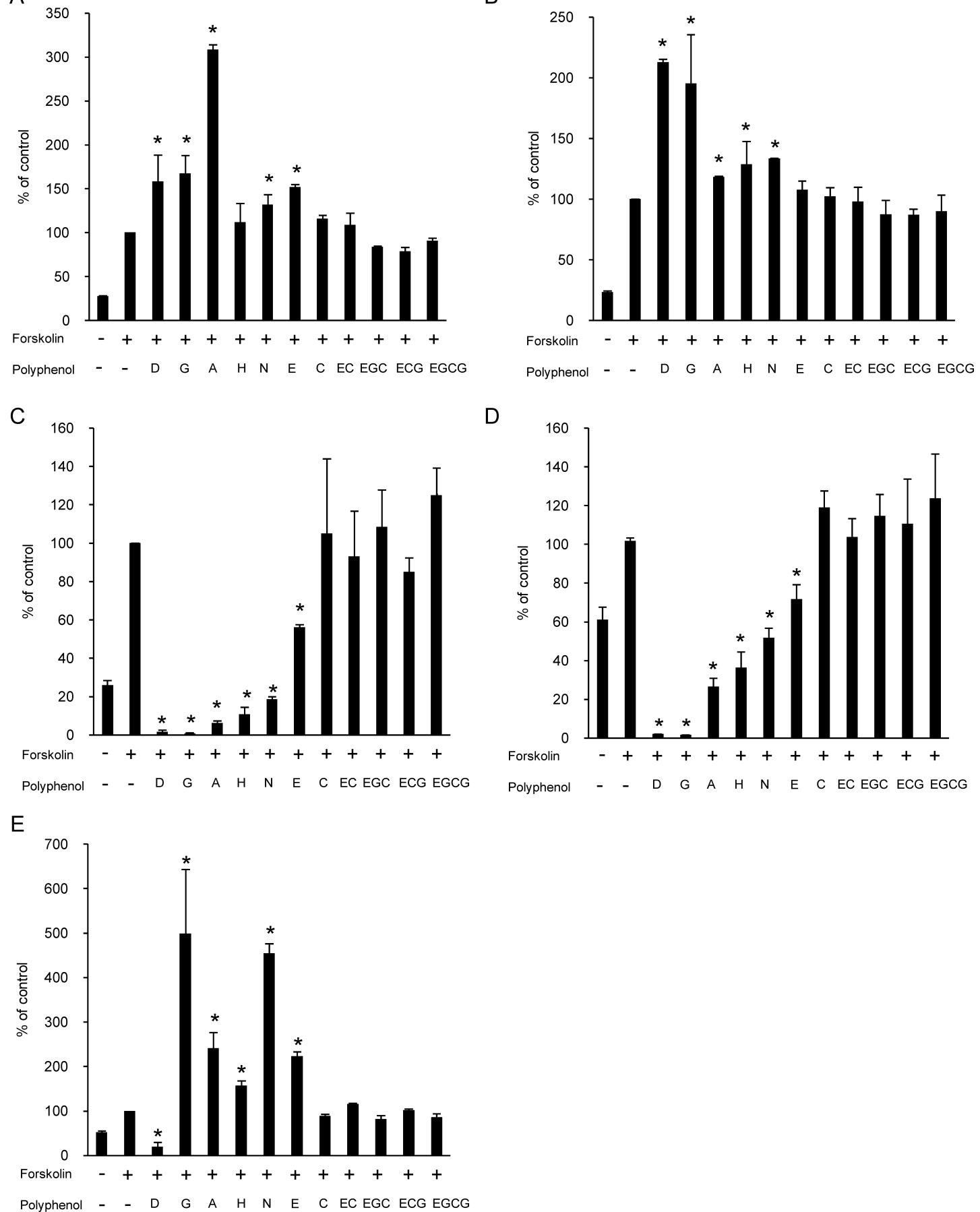

Fig. 3. Effects of 11 Polyphenols on the Levels of Steroid Hormones Produced by Forskolin-Stimulated NCI-H295R Cells

(A) Pregnenolone, (B) dehydroepiandrosterone (DHEA), (C) deoxycorticosterone, (D) androstenedione, and (E) 17 $\alpha$-hydroxyprogesterone NCI-H295R cells ( $2 \times 10^{6}$ cells) were cultured in the presence of $3 \mu \mathrm{m}$ forskolin with or without $30 \mu \mathrm{m}$ of one of the following polyphenols for $24 \mathrm{~h}$ : daidzein (D), genistein (G), apigenin (A), hesperetin $(\mathrm{H})$, naringenin $(\mathrm{N})$, eriodictyol $(\mathrm{E}),(+)$-catechin $(\mathrm{C}),(-)$-epicatechin $(\mathrm{EC}),(-)$-epigallocatechin $(\mathrm{EGC}),(-)$-epicatechin gallate $(\mathrm{ECG})$, or $(-)$-epigallocatechin gallate (EGCG). Cell culture supernatant samples were subjected to GC-MS to determine steroid levels. Data are expressed as mean \pm standard error values $(n=3)$. Levels of each

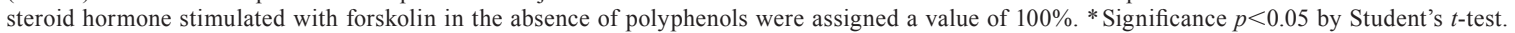

real-time RT-RCR.

Data Analysis Data are expressed as mean \pm standard error values and analyzed for statistical significance using the Student's $t$-test.

\section{RESULTS}

Chromatograms of the nine steroid hormones and internal standard are shown in Fig. 2A. Calibration curves, ranges, the correlation coefficient, limit of detection (LOD), limit of quantitation (LOQ), and the recovery rates from the cell culture supernatant $(n=5)$ are shown in Table 2. The LOD and LOQ were determined as the concentration of the nine steroid hormones giving a signal-to-noise ratio of 3 for LOD and 10 for LOQ. The recovery rates from the cell culture supernatant were estimated for a spiked concentration of $250 \mathrm{ng} / \mathrm{mL}$. A 

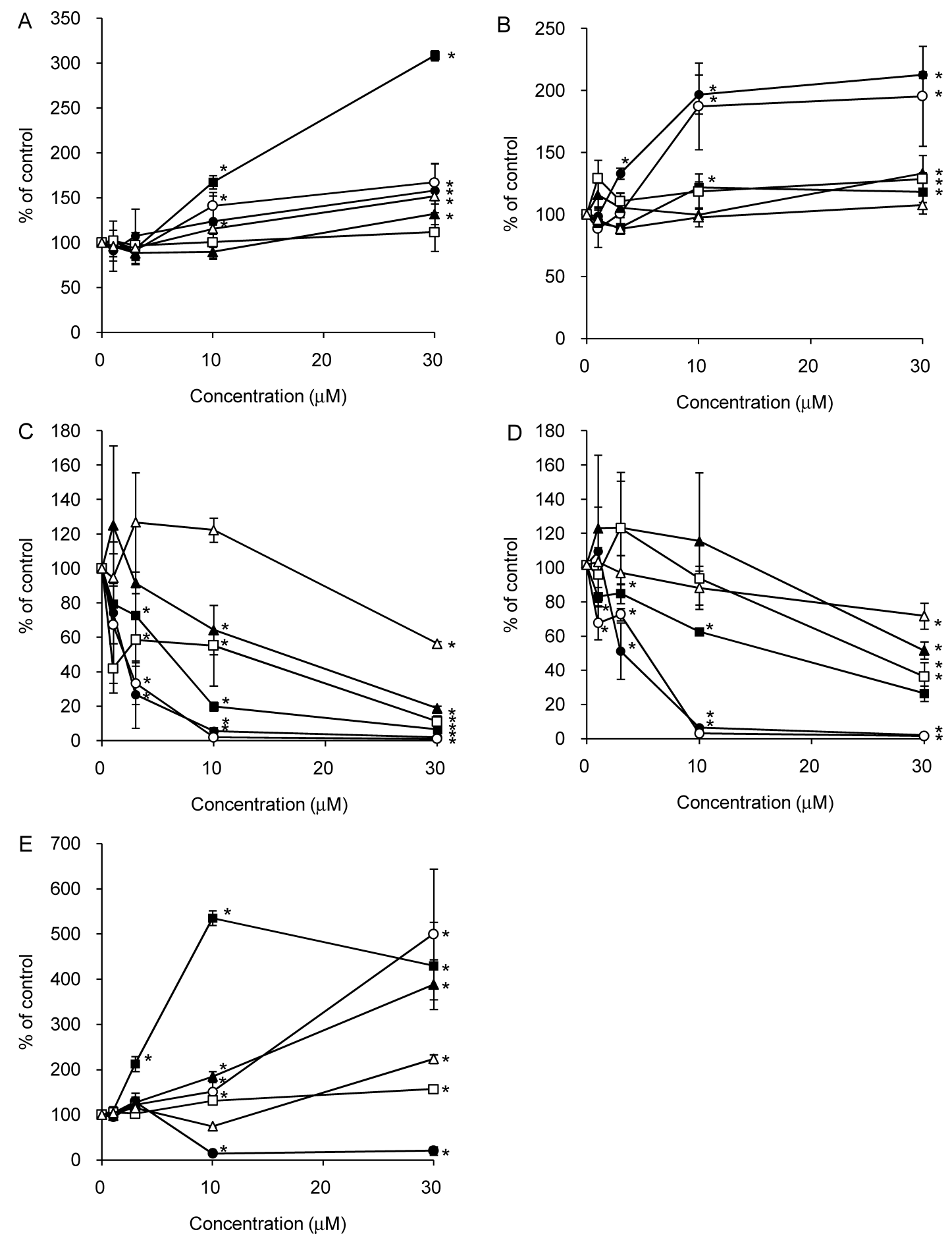

Fig. 4. Dose-Dependent Effects of Polyphenols on the Levels of Steroid Hormones Produced by Forskolin-Stimulated NCI-H295R Cells

(A) Pregnenolone, (B) dehydroepiandrosterone (DHEA), (C) deoxycorticosterone, (D) androstenedione, and (E) $17 \alpha$-hydroxyprogesterone NCI-H295R cells ( $2 \times 10^{6}$ cells) were cultured in the presence of $3 \mu \mathrm{m}$ of forskolin with or without $0-30 \mu \mathrm{m}$ of one of the following polyphenols for $24 \mathrm{~h}$ : daidzein (closed circle), genistein (open circle), apigenin (closed square), hesperetin (open square), naringenin (closed triangle), or eriodictyol (open triangle). Cell culture supernatant samples were subjected to GC-MS to determine the levels of steroid hormones. Data are expressed as mean \pm standard error values $(n=3)$.Levels of each steroid hormone stimulated with forskolin in the absence of polyphenols were assigned a value of $100 \%$. $*$ Significance at $p<0.05$ by Student's $t$-test.

chromatogram of forskolin-stimulated cell culture supernatant is shown in Fig. 2B. The chromatogram clearly shows the separation of nine steroid hormones and no influence of the matrix. Calibration curves using the internal standard method showed excellent linearity for all nine steroid hormones (correlation coefficient, 0.993-0.999). The recovery rates from the cell culture supernatant were also good, ranging from 97.2

\section{3 to $107.5 \pm 6.7 \%$.}

Pregnenolone, DHEA, deoxycorticosterone, androstenedione, and $17 \alpha$-hydroxyprogesterone levels were significantly increased by 3.61-, 4.33-, 3.84-, 1.66-, and 1.89-fold, respectively, by the stimulation of NCI-H295R cells with $3 \mu \mathrm{M}$ of forskolin $(p<0.05$; Fig. 3). Estradiol, testosterone, progesterone, and aldosterone levels were below the limit of detection 

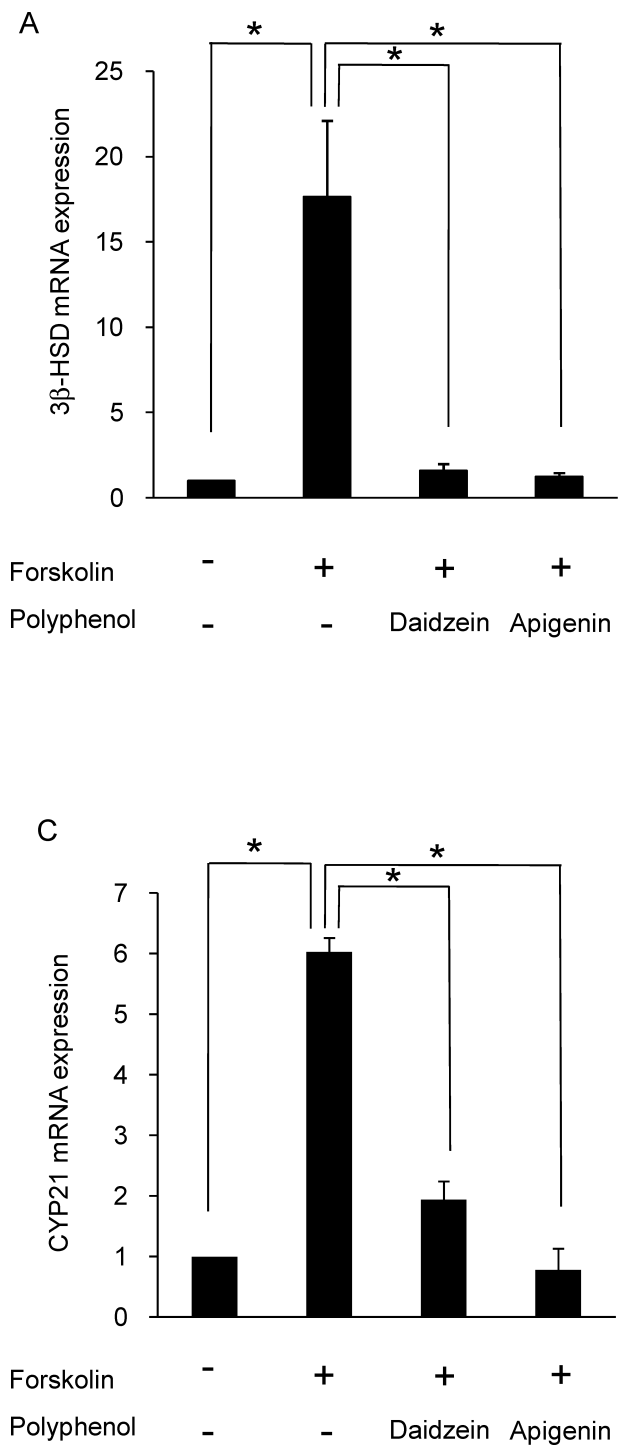

B

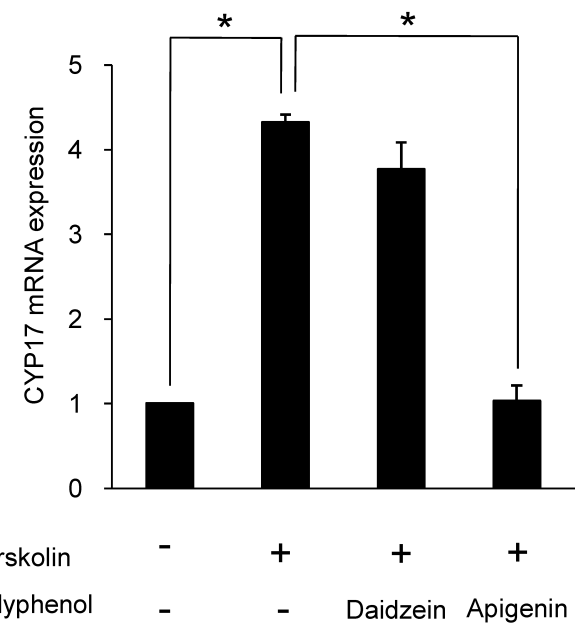

Fig. 5. Effects of Apigenin on the Expression Levels of Steroidogenic Enzyme mRNA

(A) $3 \beta$-Hydroxysteroid dehydrogenase $\left(3 \beta\right.$-HSD), (B) CYP17, and (C) CYP21 NCI-H295R cells $\left(2 \times 10^{6}\right.$ cells) were cultured in the presence of $30 \mu \mathrm{M}$ of forskolin and $1000 \mu \mathrm{m}$ of apigenin for $24 \mathrm{~h}$. The mRNA expression levels of three steroidogenic enzymes were determined by real-time reverse transcription polymerase chain reaction. Data are expressed as mean \pm standard error values $(n=3)$. The relative rate of mRNA expression in the absence of both forskolin-stimulation and apigenin is expressed as 1. * Significance at $p<0.05$ by Student's $t$-test.

of the corresponding calibration curves. We next examined the effects of the 11 polyphenols at the final concentration of $30 \mu \mathrm{M}$ on the steroid hormone levels produced by the forskolin-stimulated cells. Pregnenolone levels were significantly higher in the presence of daidzein, genistein, apigenin, naringenin, and eriodictyol than in the absence of polyphenols $(p<0.05$; Fig. 3A). Similarly, the levels of DHEA were significantly higher in the presence of daidzein, genistein, apigenin, hesperetin, and naringenin than in the absence of polyphenols $(p<0.05$; Fig. 3B). On the other hand, the levels of deoxycorticosterone were significantly lower in the presence of daidzein, genistein, apigenin, hesperetin, naringenin, and eriodictyol than in the absence of polyphenols $(p<0.05$; Fig. 3C). Androstenedione levels were significantly lower in the presence of daidzein, genistein, apigenin, hesperetin, naringenin, and eriodictyol than in the absence of polyphenols $(p<0.05$; Fig. 3D). $17 \alpha$-Hydroxyprogesterone levels were significantly lower in the presence of daidzein, but significantly higher in the presence of genistein, apigenin, hesperetin, naringenin, and eriodictyol than in the absence of polyphenols $(p<0.05$; Fig. $3 \mathrm{E})$. The effects of catechins, EC, EGC, ECG, and EGCG on steroid hormone levels produced by forskolin-stimulated NCIH295R cells were negligible (Fig. 3).

In cultured forskolin-stimulated NCI-H295R cells, genistein, apigenin, and eriodictyol significantly increased the levels of pregnenolone in the cell culture supernatant in a dose-dependent manner ( $p<0.05$; Fig. 4A). Similarly, daidzein, genistein, and apigenin significantly increased the levels of DHEA in a dose-dependent manner $(p<0.05$; Fig. 4B). On the other hand, daidzein, genistein, apigenin, hesperetin and naringenin significantly decreased the levels of deoxycorticosterone in a dose-dependent manner ( $p<0.05$; Fig. 4C). Daidzein, genistein, and apigenin significantly decreased the levels of androstenedione in a dose-dependent manner $(p<0.05$; Fig. 4D). Daidzein significantly decreased $(p<0.05)$, while genistein, apigenin, hesperetin, and naringenin significantly increased $(p<0.05)$ the levels of $17 \alpha$-hydroxyprogesterone in a dose-dependent manner (Fig. 4E). 
Cholesterol

$\downarrow$ CYP11A1<smiles>CC(O)C1CCC2C1CCC1C3CCC(O)CC3CC12</smiles>

Pregnenolone

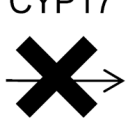

$17 \alpha-$ Hydroxypregnenolone

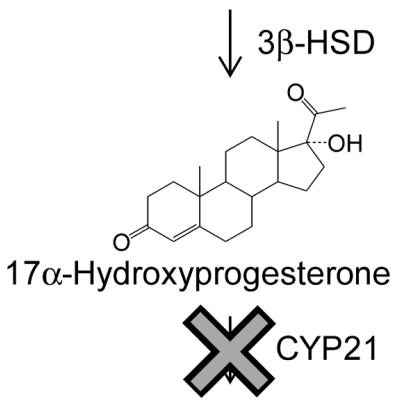

11-deoxycortisol<smiles>OCC1CCC2C1CCC1C3CCC(O)CC3CCC21</smiles>

Deoxycorticosterone

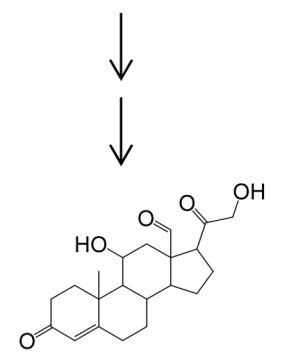

Aldosterone

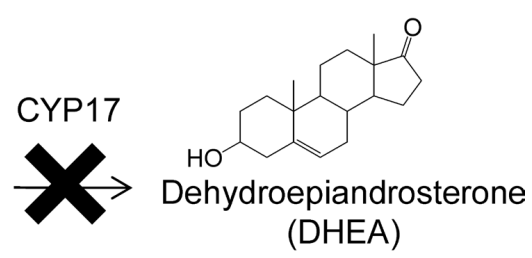

$3 \beta-H S D$

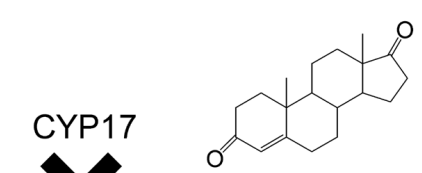

Androstenedione $\downarrow 17 \beta-H S D$<smiles>O=C1CCC23CCC4C(O)CCC4CCC2CC3C1</smiles>

Cortisol<smiles>C1CC1</smiles>

Cortisone
Testosterone<smiles>[13CH2][13CH2][13CH3]</smiles><smiles>CC1CCC2C1CC1CC3C4CCC(O)CC4CCC3(O)CCC12</smiles>

Estradiol

Fig. 6. Apigenin's Points of Intervention in Steroidogenesis

In summary, daidzein dose-dependently increased the DHEA levels, while dose-dependently decreasing the levels of androstenedione, deoxycorticosterone, and $17 \alpha$ hydroxyprogesterone, suggesting inhibition of $3 \beta$-HSD and CYP21 by this polyphenol. Genistein increased the levels of pregnenolone, DHEA, and $17 \alpha$-hydroxyprogesterone, while dose-dependently decreasing the levels of androstenedione and deoxycorticosterone, suggesting inhibition of $3 \beta$-HSD, CYP17, and CYP21. Hesperetin decreased the levels of androstenedione and deoxycorticosterone, while slightly increasing $17 \alpha$-hydroxyprogesterone levels, suggesting inhibition of $3 \beta$-HSD, CYP17, and CYP21. Naringenin dose-dependently decreased deoxycorticosterone levels, while dose-dependently increasing $17 \alpha$-hydroxyprogesterone levels, suggesting inhibition of $3 \beta$-HSD, CYP17, and CYP21. Eriodictyol slightly, but dose-dependently increased pregnenolone levels, while slightly decreasing androstenedione and deoxycorticosterone levels, suggesting inhibition of $3 \beta$-HSD, CYP17, and CYP21. Apigenin markedly increased pregnenolone and $17 \alpha$-hydroxyprogesterone levels and slightly increased DHEA levels, while dose-dependently decreasing androstenedione and deoxycorticosterone levels, suggesting inhibition of $3 \beta$-HSD, CYP17, and CYP21. There are reports of daidzein, genistein, apigenin, and naringenin inhibiting $3 \beta$-HSD, ${ }^{9-11)}$ and similar reports of daidzein and genistein inhibiting CYP21. ${ }^{12}$ However, the inhibitory effect of apigenin on CYP17 and CYP21 has not yet been reported. The present study revealed a new inhibitory effect of apigenin on CYP17 and CYP21. Consequently, we examined the inhibitory effects of apigenin on CYP17 and CYP21 mRNA by RT-PCR.

The expression of $3 \beta-H S D, C Y P 17$, and $C Y P 21$ mRNA upon forskolin stimulation with or without apigenin was significantly higher in forskolin-stimulated cells than in the controls $(p<0.05)$. It has been reported that daidzein inhibits $3 \beta$-HSD and CYP21, but not CYP17. ${ }^{12)}$ Therefore, daidzein was used as a positive control for the inhibitory substance. Daidzein significantly decreased forskolin-induced increases in the expression levels of $3 \beta-H S D$ and $C Y P 21$ mRNA $(p<0.05)$, but did not decrease forskolin-induced increases in the expression levels of CYP17 (Fig. 5). Next, apigenin significantly decreased forskolin-induced increases in the expression levels of $3 \beta-H S D$, $C Y P 17$, and CYP21 mRNA ( $p<0.05$; Fig. 5), demonstrating the 
inhibitory effects of apigenin on the expression of $3 \beta-H S D$, CYP17, and CYP21.

\section{DISCUSSION}

Several methods have been reported for determining steroid hormones by GC-MS. ${ }^{14,15)}$ However, these methods are somewhat complicated because they require two or three reactions, such as $n$-butylboronic cyclization, methyloxime derivatization, and TMS derivatization. In this study, we improved the simultaneously determination of nine steroid hormones by simplifying the process and ensuring accuracy by TMS derivatization using a mixture of hexamethyldisilazane-trimethylchlorosilane-pyridine in a ratio of $2: 1: 10$.

Polyphenols are abundant in the human diet and are of particular interest because they are implicated in protective actions against diseases such as cancer, cerebrovascular diseases, and neurodegenerative diseases.7) Several polyphenols have been shown to have inhibitory effects against steroidogenic enzymes; for example, daidzein, genistein, apigenin, and naringenin act against $3 \beta$-HSD, while isoflavones act against $3 \beta$-HSD and aromatase. ${ }^{9-13)}$ In these reports, only one or two steroid hormones have been determined to confirm the inhibitory effects of polyphenols on $3 \beta$-HSD and aromatase. Accordingly, we tested the effects of polyphenols on steroidogenic pathways by simultaneously measuring levels of nine steroid hormones. We found that isoflavones (daidzein and genistein), one flavone (apigenin), and three flavanones (hesperetin, naringenin, and eriodictyol) dose-dependently decreased the levels of androstenedione and deoxycorticosterone produced by forskolin-stimulated NCI-H295R cells, suggesting inhibition of $3 \beta$-HSD. These inhibitory effects were in good agreement with the results of previous studies. ${ }^{9-11)}$ Daidzein carries a hydroxyl group at $\mathrm{C} 7$ of the A-ring and competes with $3 \beta$-HSD substrates because of its steric structure and strong electron affinity with the active center of $3 \beta$-HSD.9) $\mathrm{Ge}-$ nistein, apigenin, hesperetin, naringenin, and eriodictyol also carry a hydroxyl group at $\mathrm{C} 7$ of the A-ring, suggesting that their inhibitory mechanisms are similar to those of daidzein.

The effect of apigenin was particularly prominent on levels of pregnenolone produced by forskolin-stimulated NCI-H295R cells. In addition to the hydroxyl group at $\mathrm{C} 7,{ }^{9)}$ a phenolic $\mathrm{B}$ ring at $\mathrm{C} 3$ of the pyran ring is important for the inhibitory effects of the isoflavones daidzein and genistein on 3 $\beta$-HSD. ${ }^{13)}$ Flavones such as apigenin do not carry such a phenolic B ring, and this may explain their stronger inhibitory effect. On the other hand, apigenin increased the levels of pregnenolone and $17 \alpha$-hydroxyprogesterone more than isoflavones, suggesting that apigenin inhibits CYP17, CYP21, and 3 $\beta$-HSD. Simultaneous determination of steroid hormones has revealed novel inhibitory effects of apigenin on CYP17 and CYP21. Apigenin appeared to inhibit expression of the above three enzymes, as confirmed by quantitative real-time RT-PCR. The inhibitory effects on multiple steroidogenic enzymes were shown by our approach; namely, simultaneously examining the levels of multiple steroid hormones. Indeed, this study is the first to show the inhibitory effects of apigenin on CYP17 and CYP21. Apigenin's points of intervention in steroidogenesis are shown in Fig. 6.

Comprehensive understanding of steroidogenic pathways is important to understand the actions of pharmaceutical agents and food constituents such as polyphenols on steroid hormone levels. Furthermore, such understanding will contribute to the control of steroid hormone levels in patients with excessive steroid hormone production.

Acknowledgements This study was supported in part by a Grant from the Strategic Research Foundation Grant-aided Project for Private Universities from the Ministry of Education, Culture, Sports, Science and Technology (MEXT) of Japan, 2010-2014 (S1001030).

\section{REFERENCES}

1) Ullerås E, Ohlsson A, Oskarsson A. Secretion of cortisol and aldosterone as a vulnerable target for adrenal endocrine disruptionscreening of 30 selected chemicals in the human H295R cell model. J. Appl. Toxicol., 28, 1045-1053 (2008).

2) Anagnostis P, Athyros VG, Tziomalos K, Karagiannis A, Mikhailidis DP. Clinical review: The pathogenetic role of cortisol in the metabolic syndrome: a hypothesis. J. Clin. Endocrinol. Metab., 94, 2692-2701 (2009).

3) Kimura Y, Sumiyoshi M, Suzuki T, Suzuki T, Sakanaka M. Effects of water-soluble low-molecular-weight $\beta$-1,3-D-glucan (branch $\beta$-1, 6) isolated from Aureobasidium pullulans 1A1 strain black yeast on restraint stress in mice. J. Pharm. Pharmacol., 59, 1137-1144 (2007).

4) Delarue J, Matzinger O, Binnert C, Schneiter P, Chioléro R, Tappy L. Fish oil prevents the adrenal activation elicited by mental stress in healthy men. Diabetes Metab., 29, 289-295 (2003).

5) Kim YR, Lee SY, Shin BA, Kim KM. Panax ginseng blocks morphine-induced thymic apoptosis by lowering plasma corticosterone level. Gen. Pharmacol., 32, 647-652 (1999).

6) Manach C, Scalbert A, Morand C, Rémésy C, Jiménez L. Polyphenols: food sources and bioavailability. Am. J. Clin. Nutr., 79, 727-747 (2004)

7) Pandey KB, Rizvi SI. Plant polyphenols as dietary antioxidants in human health and disease. Oxid. Med. Cell. Longev., 2, 270-278 (2009).

8) Pilšáková L, Riečanský I, Jagla F. The physiological actions of isoflavone phytoestrogens. Physiol. Res., 59, 651-664 (2010).

9) Ohno S, Matsumoto N, Watanabe M, Nakajin S. Flavonoid inhibition of overexpressed human $3 \beta$-hydroxysteroid dehydrogenase type II. J. Steroid Biochem. Mol. Biol., 88, 175-182 (2004).

10) Lacey M, Bohday J, Fonseka SM, Ullah AI, Whitehead SA. Doseresponse effects of phytoestrogens on the activity and expression of $3 \beta$-hydroxysteroid dehydrogenase and aromatase in human granulosa-luteal cells. J. Steroid Biochem. Mol. Biol., 96, 279-286 (2005).

11) Hsia SM, Yeh CL, Kuo YH, Wang PS, Chiang W. Effects of adlay (Coix lachryma-jobi L. var. ma-yuen $\mathrm{S}_{\mathrm{TAPF}}$.) hull extracts on the secretion of progesterone and estradiol in vivo and in vitro. Exp. Biol. Med. (Maywood), 232, 1181-1194 (2007).

12) Ohno $S$, Shinoda $S$, Toyoshima $S$, Nakazawa H, Makino T, Nakajin S. Effects of flavonoid phytochemicals on cortisol production and on activities of steroidogenic enzymes in human adrenocortical H295R cells. J. Steroid Biochem. Mol. Biol., 80, 355-363 (2002).

13) Le Bail JC, Champavier Y, Chulia AJ, Habrioux G. Effects of phytoestrogens on aromatase, $3 \beta$ - and 17 $\beta$-hydroxysteroid dehydrogenase activities and human breast cancer cells. Life Sci., 66, 1281-1291 (2000).

14) Ichimura K, Yamanaka H, Chiba K, Shinozuka T, Shiki Y, Saito K, Kusano S, Ameniya S, Oyama K, Nozaki Y, Kato K. Simultaneous quantitative measurement of fourteen adrenal steroids by capillary column gas chromatography-mass spectrometry, and its clinical application. J. Chromatogr. A, 374, 5-16 (1986). 
15) Christakoudi S, Cowan DA, Taylor NF. Steroids excreted in urine by neonates with 21-hydroxylase deficiency: characterization, using GC-MS and GC-MS/MS, of the D-ring and side chain structure of pregnanes and pregnenes. Steroids, 75, 34-52 (2010).

16) Mesiano S, Katz SL, Lee JY, Jaffe RB. Phytoestrogens alter adrenocortical function: genistein and daidzein suppress glucocorticoid and stimulate androgen production by cultured adrenal cortical cells. J. Clin. Endocrinol. Metab., 84, 2443-2448 (1999).

17) Haas CE, Brazeau D, Cloen D, Booker BM, Frerichs V, Zaranek C, Frye RF, Kufel T. Cytochrome P450 mRNA expression in peripheral blood lymphocytes as a predictor of enzyme induction. Eur. J. Clin. Pharmacol., 61, 583-593 (2005).

18) Peng N, Kim JW, Rainey WE, Carr BR, Attia GR. The role of the orphan nuclear receptor, liver receptor homologue-1, in the regulation of human corpus luteum $3 \beta$-hydroxysteroid dehydrogenase type II. J. Clin. Endocrinol. Metab., 88, 6020-6028 (2003).

19) Ye P, Nakamura Y, Lalli E, Rainey WE. Differential effects of high and low steroidogenic factor-1 expression on CYP11B2 expression and aldosterone production in adrenocortical cells. Endocrinology, 150, 1303-1309 (2009).

20) Hilscherova K, Jones PD, Gracia T, Newsted JL, Zhang X, Sanderson JT, Yu RM, Wu RS, Giesy JP. Assessment of the effects of chemicals on the expression of ten steroidogenic genes in the H295R cell line using real-time PCR. Toxicol. Sci., 81, 78-89 (2004).

21) Livak KJ, Schmittgen TD. Analysis of relative gene expression data using real-time quantitative PCR and the $2^{-\Delta \Delta C_{\mathrm{t}}}$ Method. Methods, 25, 402-408 (2001). 